Filozofia Publiczna i Edukacia Demokratycina

Tom 7 • 2018 • Numer 2 / Tom 8 • 2019 • Numer 1 • Art. \#1 • S. 109-121

DOI: 10.14746/fped.2018.1.2.2019.8.1.1

Www.filozofiapubliczna.amu.edu.pl • ISSN 2299-1875

@) (reative Commons BY-NC-ND 4.0

\title{
On the construction of the system for forensic psscholinguistics
}

Shaogang Yang*, lhuo liw**

Abstruct: Forensic psycholinguistics is an emerging interdisciplinary subject that makes use of the psychological methods to analyze the linguistic phenomena in legal activities and therefore it is of the multiple and cross-disciplinary nature. In ancient Chinese culture there were written expressions with thoughts of forensic psycholinguistics and its practices. In Western countries the research started from European societies at the end of 19th century when Münsterberg and Cattell and some other scholars acted as the pioneers of this domain. After the WWII the research center of forensic psycholinguistics gradually moved to the United States where the research of legal psychology and the use of psychological methods greatly facilitate the study and practices of forensic psycholinguistics. Its study object aims at the linguistic behavior in such legal activities as legislation, judicial, the obeying of the law and transgression, and its task should be the research on the behavior of the legal language in both levels of consciousness and unconsciousness. The construction of the system for forensic psycholinguistics should start from the perspectives of linguistic psychology of legislation, judicial, the enforcement and obeying of the law and the legal publicity so that a cross-cultural emerging subject with its values of practical application could be created.

Keywords: forensic psycholinguistics, linguistic behavior, theoretical system

\footnotetext{
* School of English and Education, Guangdong University of Foreign Studies e-mail: ysgrime@163.com

** School of English and International Business, Guangdong University of Foreign Studies e-mail: wawashiHannah@163.com
} 


\section{Introduction}

Forensic psycholinguistics is an emerging interdisciplinary subject which makes use of the psychological methods to analyze the linguistic behaviors in legal activities and thus it has the cross-disciplinary and integration nature. ${ }^{1}$ Through the disciplinary interactions among law, linguistics and psychology, forensic psycholinguistics has become a new domain that draws lessons from the advantages of each discipline and studies their common legal language psychology. Since ancient times, both domestic and foreign jurists and linguists have studied the psychological problems in forensic linguistic behaviors from their respective perspectives. At present, more and more experts and scholars have realized the status and value of psychology in the application of legal language and they have become consciously or unconsciously involved in the field of forensic psycholinguistics. However, because of its relations with three different research areas, so far, it has not grown into a complete discipline which should have had its own independent theoretical system. Therefore, based on the reality of the psychological researches in forensic linguistics in China, combining the researches in foreign developed countries, the authors want to put forward a newly founded theoretical conception to establish forensic psycholinguistics in China which is not only the needs of China's present social practice, but also the historical necessity for Chinese philosophy and social science to "go abroad".

\section{The historical reflection of forensic psscholinguistics in China}

The Chinese nation has a long history of civilization for more than 5,000 years. In ancient Chinese society, the legal language with written records has a history of more than 4,000 years since the establishment of legal system in Xia dynasty (about 2070BC-1600BC). The expression "In Xia dynasty,

$1 \mathrm{Ma} \mathrm{Ai,} \mathrm{"An} \mathrm{exploration} \mathrm{of} \mathrm{the} \mathrm{basic} \mathrm{theories} \mathrm{in} \mathrm{forensic} \mathrm{psycholo-}$ gy", Journal of Gansu Political Science and Law Institute 2010, no. 4, pp. 51-59. 
there was a crusade, so the Yu Criminal Law came into being; in Shang dynasty, there was a crusade, so the Tang Criminal Law came into being" ${ }^{2}$ is believed to be the earliest forensic linguistic evidence with written records. It is said that the Five Forms of Punishments in Xia dynasty were amounting to more than three thousand items, which indicates the early development of legal texts recorded in written Chinese. But up to now, no Chinese characters have been found in Xia dynasty, so it belongs to the legendary era. In Shang dynasty (about 1600BC-1046BC), oracle bone inscriptions appeared and thus it entered the era of letters, but no written records related to the Yu Criminal Law or Tang Criminal Law have been found in oracle bone inscriptions. After the establishment of Western Zhou dynasty (1046BC-256BC), the rulers absorbed lessons from Xia and Shang dynasties when excessive attention was paid to the criminal punishments, and they advocated that "The emperor's reign contains no relation but virtue", thus establishing the thought of legal construction of promoting virtue and cautious employment of penalty. In the Spring and Autumn period (770BC-221BC), Confucius carried on and developed the thought of moral psychology from Ji Dan, the duke of Zhou dynasty, in making rituals and creating music, ${ }^{3}$ which formed the Confucian moral culture of China for more than 2,500 years. Although there were numerous legal texts and rules and regulations throughout various ancient dynasties, the Chinese society has not been built into a real legal society up to now. The historical reasons herein are thought-provoking. Besides, although ancient Chinese legal texts were lacking of any empirical analysis or expression of legal language psychology, as a systematic discipline, forensic psycholinguistics has not yet formed a complete theoretical system up to the present time both in China and in other countries.

1 Ruan Yuan, Notes on the Thirteen Classics, vol. 4, China Publishing House, Beijing 2009.

3 Yang Shaogang, "Zhougong Ji Dan's Thought of Moral Psychology and Its Modern Interpretation”, Collected Papers of the Second International Academic Conference on Zhou and Qin Dynasty's Ethical Culture and Modern Moral Values, Shaanxi Normal University Press, Shaanxi 2012. 


\subsection{The thought of forensic psscholinguistics in ancient Chinese legal texts}

The first monograph on legal language problems in written form in China is the Rites of Zhou in the Warring States period (475BC-221BC), among which many specific expressions of legal language psychology are involved, "Hear the litigation and know the actual situation of the litigant with Five Observing: the first is to observe his words; the second is to observe his countenance; the third is to observe his breath; the fourth is to observe his hearing; the fifth is to observe his gaze". ${ }^{4}$ Zheng Xuan (127AD-200AD), the Confucian scholar of the late Eastern Han dynasty, as to the Five Observing, made the following comments, "The first is to observe the litigant's language expression, if he lacks argument then his speech will be incoherent; the second is to observe his facial expression, if he lacks argument then he will blush red in the face; the third is to observe his breath when he speaks, if he lacks argument then he will be out of breath; the fourth is to observe his auditory response, if he lacks argument then he will lose hearing; the fifth is to observe his eye expression, if he lacks argument then he will look confused". ${ }^{5}$ In particular, the first "to observe his words" means to hear the litigant's statement, which can be said to be a wonderful expression of legal language psychology.

Rulers of later generations also attached great importance to the establishment of legal system. From the Rites of Zhou of the Western Zhou dynasty, through the Nine Chapters Law of the Western Han dynasty, the Kai Huang Law of the Sui dynasty, the Tang Dynasty Law, the Song Dynasty Criminal Law, until the Ming Dynasty Law, and the Qing Dynasty Law, etc., a great number of profound thoughts of forensic psycholinguistics were implied in them. The comments on these legal texts by some scholars of later generations were the very model of the application of legal language to psychological analysis. For example, Tang Code of the Tang Dynasty commented on self-surrender

4 Ruan Yuan, op. cit.

' Zheng Xuan, Notes on Rites of the Zhou, Vol. 35, Shanghai Classics Publishing Press, Shanghai 2010. 
and self-renewal as follows, "Not to mend the fault that one has made is to err indeed. If the fault can be reformed now, and if one could voluntarily confess one's crime, which could be exempted. If someone reports an offender, no matter whether the lawsuit has been treated, it means that the crime has been issued. And even though the criminal takes the initiative to court and surrender, it could not be treated as voluntary surrender". ${ }^{6}$ In this paragraph the definition of voluntary surrender and repentance has been clearly defined from the perspective of forensic linguistic psychology. The voluntary surrender means that the crime has happened but the government has not detected it yet and there is no public report, the criminal, out of the mind of penitence, voluntarily goes to the government to surrender. According to the law of the Tang Dynasty, such behavior can exempt from criminal punishment. The repentance refers to that the criminal behavior has happened, and after the escape he or she is forced to go to the government to surrender. In this case only commutation of punishment can be done for such repentance behavior, but not exempt from punishment. This legal text, with the employment of precise legal language, examines the criminal psychology, and makes a clear linguistic psychological analysis of the nature, circumstance, harm and punishment of voluntary surrender and repentance, which can be said to be extraordinary.

\subsection{The development of forensic psycholinguistis in modern China}

Although the thoughts of forensic psycholinguistics in ancient China are as vast as the ocean, they are only sporadically reflected in some legal texts, notes and commentaries of the ancient classics, and in such legal activities as court verdicts and judicial proceedings and so on, but have not been scientifically developed as a specialized discipline. Since the beginning of the $20^{\text {th }}$ century, with the introduction of western psychology into China, some scholars embarked on the translation of foreign monographs such as Forensic

6 Guo Chengwei, "The Features of the Traditional Legal Languages Embodied in LONG JIN FENG SUI PAN of the Law of Tang Dynasty", The Jurist 2006, vol. 5, pp. 53-58. 
Psychology, Penal Psychology and Criminal Psychology ${ }^{7}$, among which many phenomena of forensic psycholinguistics are involved. For example, in Forensic Psychology ${ }^{8}$, the authors explored the psychology of witness testimony and analyzes the credibility and discrimination of the witness who tells the truth and the witness who commit perjury, by using the rules of mental activities such as perception, memory, attention, emotion and so on. However, at that time, there were few studies or researches on forensic psycholinguistics by Chinese scholars. During the three decades from the foundation of the People's Republic of China in 1949 to 1979, the domestic studies on forensic psychology almost stopped, not to mention the studies on forensic psycholinguistics. Since the reform and opening up from 1980s, some legal workers, psychologists and linguists of the older generation in China began to place a new emphasis on the studies on forensic psychology and linguistic psychology, and accordingly, the psychological phenomenon of legal language began to be paid attention to. Especially since the 1980s and 1990s of the last century, the combination of linguistics, neuroscience and brain science, as well as the research methods of experimental psychology brought about the successive emergence of neurolinguistics and psycholinguistics and such emerging disciplines so that Shuy, an American forensic linguist, said that, "It is hard to imagine any field in our life where linguistics has not been involved." Until now, there are tens of academic works related to forensic linguistics which have been published in domestic academic circles, including some works that are related to forensic psychology. However, we still regrettably say that there is not a single monograph on forensic psycholinguistics. Even in some European and American developed countries, there is not a complete theoretical system of forensic psycholinguistics.

1 Luo Dahua, Judicial Psychology, People's Education Press, Beijing 2005.

8 Robert Maynard Hutchins, Donald Sleisinger, "Legal psychology", Psychological Review 1929, vol. 36, no. 1, pp. 13-26.

9 Roger W. Shuy, Anna Shnukal (eds), Language Use and the Uses of Language, Georgetown University Press, Washington, DC 1996, pp. 222-234. 


\section{Social development calling for forensic psycholinguistics}

Due to the limitations of history and times, it was not until the early 1980s, with the implementation of China's reform and opening up policy, that the studies on forensic psycholinguistics started from scratch, from less to more. Through the last forty years or so, scholars in the field of linguistics, psychology and law have studied the psychological phenomenon of legal language from their own perspectives. Though there is not a single monograph on forensic psycholinguistics up to now, its basic theoretical framework can be constructed through systematic arrangement. Generally speaking, the studies on forensic psycholinguistics in China since the reform and opening up are mainly reflected in the following aspects:

\subsection{From forensic linguistics to forensic psycholinguistics, psschology plays an increasingly prominent role in the studies on the phenomenon of legal language}

The studies on forensic psycholinguistics were originally reflected in the respective studies of scholars of linguistics, law and psychology. At the end of 1970s, Gao Chao, a scholar at the former Beijing Institute of Political Science and Law, when compiling the Chinese Course, for the first time with foresight proposed to study legal language ${ }^{10}$, though he has not yet put forward such a view from the psychological perspective. At the beginning of 1980s, Ning Zhiyuan et al., a pioneer in the study of legal instruments at China University of Political Science and Law, published a book, A Talking about Grammar with Political and Legal Workers calling for people to pay more attention to the phenomenon of legal language. ${ }^{11}$ In 1985 , Chen Jiong published articles "Forensic Linguistics Should Be Established" and "A Probe into Forensic Linguistics", which played a positive role in promoting the study on contemporary Chinese forensic linguistics. After that, more and more Chinese scholars of linguistics and law wrote a great number of articles

10 Song Beiping, Legal Language, China University of Political Science and Law Press, Beijing 2012.

" Ning Zhiyuan, A Talking about Grammar with Political and Legal Workers, China University of Political Science and Law Press, Beijing 1982. 
and monographs from the perspective of forensic linguistics, many of which touched on the study on the phenomenon of legal language. Especially in 2002, Professor Du Jinbang at Guangdong University of Foreign Studies published the article "An Overview of the Research of Forensic Psycholinguistics", which for the very first time made a clear theoretical interpretation of forensic psycholinguistics and called on the academic circle to reinforce the studies on the phenomenon of forensic psycholinguistics. Scholars of psychology, through the studies on investigation psychology, interrogation psychology, defense psychology, penalty psychology, witness testimony psychology, prisoner reformation psychology, mediation psychology and so on, are also concerned with many topics related to forensic psycholinguistics. For instance, some scholar made a psychological analysis of the failure of advertisement language, ${ }^{12}$ which involved the phonetic, grammatical and semantic errors, pragmatic rhetoric failure, linguistic misdirection, the violation of laws and regulations of language use and so on. These phenomena are still seen to have a large number in advertisement language at present, which is also a thought-provoking forensic psycholinguistics problem. Some other scholars studied the linguistic guidance strategies in investigation activity. ${ }^{13}$ In view of the psychological characteristics of the suspect, the linguistic guidance strategies are employed to change his attitude, thus producing a sound psychological effect. More and more suchlike research achievements have been made in this field, and a rising amount of attention has been paid to psychological problems involved in the application of legal language. Certainly, because of the restrict of their special professions, these scholars from different fields have explored in their own research field, but it is difficult for them to make a breakthrough in the special research on forensic psycholinguistics, which becomes a bottleneck restricting the development of forensic psycholinguistics.

1 Shi Canfang, "A Psychological Analysis of Anomie Phenomena in Advertising Language”, Applied Linguistics 1995, vol. 1, pp. 49-51.

B Bi Xiqian, "Psychological Strategy of Guidance in Criminal Interrogation", Journal of People's Public Security University of China (Social Sciences Edition) 2005, vol. 1, pp. 86-90. 


\subsection{From independence to integration, Law, linguisisis and psschology absorb and learm from each other}

In 1983, under the initiative of Professor Pan Shu, the President of Chinese Psychological Society (CPS, for short), Director of Institute of Psychology, Chinese Academy of Sciences, CPS established the professional committee of legal psychology. From 1983 to 1985, twenty provinces, municipalities and autonomous regions all over the country have successively established professional committees or preparatory committees on legal psychology, with more than one thousand members. Although the members of the Society do not specialize in forensic psycholinguistics, many of their research results involve the psychological problems of legal language in this field. In 1992, the China Society of Criminology was founded, one of the seven branches set up under which was the professional committee of criminal and correction psychology. Many studies also involve forensic psycholinguistics, for instance, the analysis of psycho-linguistic features of criminal psychology, ${ }^{14}$ the publication of the monograph Research on Inquiring Psychological Language $e^{15}$ and so on. The linguistic circle also started to pay more attention to the study on forensic linguistic psychology. In 2000, at the proposal of Professor Jiang Jianyun at Shanghai University, China Association of Forensic Linguistics (CAFL, for short) was formally established. The national and international conferences held every two years have given rise to the popularity of forensic linguistics in China, and many researchers' papers have increasingly involved the problems of forensic psycholinguistics. According to the rough estimation of the papers of the $6^{\text {th }}$ and $7^{\text {th }}$ Chinese Academic Seminar of Forensic Linguistics and the Annual Conference of CAFL, more than a fifth among all hundreds of papers which were submitted to each meeting involves the problems of forensic psycholinguistics. The scholars in legal profession and the law circle should be an important team to study the psychological phenomenon of legal language, but in the past,

${ }^{14}$ Xiao Qingping, Yang Xuyin, “A Primary Exploration of the Research on Criminal Psycholinguistics", Criminal Research 2001, vol. 5, pp. 31-36.

is Xing Wenjun, Research on Inquiring Psychological Language, Police Officer Education Press, Beijing 1997. 
they have not paid enough attention to the research of legal language, and they have even turned a blind eye to the psychological phenomenon of legal language. As the research of psychology and linguistics circle on forensic linguistics and psychological phenomenon of legal language has become more and more powerful, the law circle has also begun to change its attitude of standing upon one's pantofles and participated in the research of legal language. In 2007, China University of Political Science and Law and Intermediate People's Court of Zhengzhou worked together to hold the 1st National Seminar on the Certification of Verbal Evidence and Judicial Applications, which marked that the law circle has begun to participate in the study on forensic linguistics as a whole, in which it also involves the problems of forensic psycholinguistics. In 2008, Beijing College of Politics and Law held the $1^{\text {st }}$ National Conference on the Standardization of Legal Language, which is the first time for the law circle to systematically participate in studies on forensic linguistics, many of these studies addressing the problems of forensic psycholinguistics. Although the study on forensic psycholinguistics has not yet formed its own unique system, the co-participation and mutual absorption and learning of law, psychology and linguistics has laid a basic organizational foundation for the construction of the system of forensic psycholinguistics.

\subsection{From theory to practice, the society and times are increasingly appeading to the research of forensic psscholinguistics}

In the past, the research and exploration of forensic psycholinguistics in China was mainly carried out in theoretical ideas. Although a small number of studies involved the problems of forensic psycholinguistics in specific areas of practical justice and law enforcement, they have little impact. In other words, most of these practical studies are actually experiential studies, and it is hard for them to have a say in the field of legal profession and linguistics. Even in theoretical studies, there is a lack of a high-quality generalized theory, and it is more difficult to form shared theoretical care and provide coherent theoretical guidance to the system of forensic psycholinguistics. Certainly, with the deepening of the research, some theoretical studies have begun to attract the attention of the related judicial system. For example, Professor Luo 
Dahua's experimental research on the credibility of witness testimony has exerted great academic influence in the judicial field. The experts and scholars of law and linguistics also took notice of the roles played by psychology. Their research also revealed the contemporary appeal of psychology in the field of forensic linguistics. It is worth noticing that with the expansion of the research team, a number of subsequent talents have grown up one after another. China University of Political Science and Law, Southwest University of Political Science \& Law, Northwest University of Politics \& Law, East China University of Political Science and Law and Guangdong University of Foreign Studies and other universities recruit master's and doctoral students related to forensic psycholinguistics, and in 2011, Guangdong University of Foreign Studies recruited postgraduate students majoring in forensic psycholinguistics. This indicates that forensic psycholinguistics is attracting more and more attention, and that the research team of forensic psycholinguistics will have successors and be full of hope. Certainly, we must objectively realize that, after all, linguistics, law and psychology are different disciplines, so it is not an easy task to cultivate professionals who can master the three fields. Scholars in the three fields should, through cooperation, joint hands to form the consciousness of and reach a consensus on establishing forensic psycholinguistics. With the passage of time and the completion of conditions, the construction of the system of forensic psycholinguistics can be expected soon.

\section{International research on forensic psscholinguissics being in the assendant}

Western studies on the psychological phenomena of legal language started at the end of $19^{\text {th }}$ century and the beginning of $20^{\text {th }}$ century when Hugo Munsterberg, J. McKeen Cattell et al. pioneered in this field. ${ }^{16}$ Though many theorists and practitioners have studied the psychological phenomena of legal language in different fields and occasions, however, in the past over one hundred years, forensic psycholinguistics has

16 Yang Shaogang, "From Forensic Psychology to Forensic Psycholinguistics: A Historical Consideration”, Psychological Research 2011, vol. 4(3), pp. 1-6. 
neither in Europe nor in the United States grown into an independent discipline. It was not until the 1970s that the phenomena of the marginalization of the research on forensic psycholinguistics began to be improved. The following facts may be easy inklings.

\section{The rapid development of forensic psschology greatly promotes the research on the psschological phenomenn of legal languange}

Since 1970s, forensic psychology in the United States has entered a phase of rapid development and the research achievements in each field of forensic psychology have emerged in large numbers. Compared with 1960s when only about 100 or so articles and monographs were published each year, mid-1970s has seen an increase up to thousands of articles in the number. Some specialized journals focusing on the researches and the problems of forensic psychology have taken into shape, for instance, Criminal Justice and Behavior issued in 1974, Law and Psychology Review issued in 1975, Law and Human Behavior issued in 1977, Behavioral Science and Law issued in 1982 and Psychology, Public Policy and Law issued in 1995. The United Kingdom issued Criminal Behavior and Mental Health in 1990 and Psychology, Crime and Law in 1994. The British Psychological Society issued Legal and Criminological Psychology in 1996 and Journal of Forensic Psychology Practice in 2001. What's more, some interdisciplinary magazines related to forensic psychology were also issued successively, such as Journal of Forensic Science, American Journal of Forensic Psychiatry, Journal of Psychiatry and Law and so on. In 2001, forensic psychology, as an independent major, received acknowledgement from American Psychological Association. All of these laid a necessary academic research foundation for the construction of the system of forensic psycholinguistics and provided significant organizational guarantee.

\subsection{The psschological methods facilitate the progression of the study on forensic psycholinguissics}

The reason why the fields of law and linguistics favor the psychological research is to some extent related to the empirical research methods employed in psychology. In recent years, researchers are applying experimental methods of psychology 
to some cases and making scientific analysis and interpretation of the forensic linguistic behavior and its variables of the subjects so as to help the legal profession make more scientific and accurate legal decisions. ${ }^{17}$ As an interdisciplinary major, forensic psycholinguistics should conduct a comprehensive application of the methodology and specific research methods of law, linguistics and psychology, through the explanation and prediction of various kinds of behaviors in forensic linguistics, to improve the legal efficiency. At present, forensic psycholinguistics has played a crucial part in the analysis of the following cases: threat assessment, authorship attribution, perjury, workplace violence, discourse analysis of criminal suspects, and so on.

\subsubsection{Psychological assessment of threetering langunages}

It refers to the psychological analysis of the threatening materials in verbal or written forms. Based on the analysis, researchers can determine the motivation, personality, demographic characteristics of the criminal suspect and the psychological analysis of the risk of threats by the threatening person. For example, the Federal Bureau of Investigation's analysis of the relationship between the language used in threatening communication and the risk of potential violence by a threatening person is a typical example of the application of forensic psycholinguistics.

\subsection{Authorship attribution}

It employs the psychological methods to analyze the author's writing style such as syntactic structure, words selection, spelling, handwriting, punctuation mark and so on, and compare these characteristics with the materials written by the suspect so that it can be determined whether it was written by the suspect. Also, it can be used to make a linguistic psychological analysis of the suicide notes to confirm whether it is suicide.

\subsection{A psschological analysis of witness tessimony}

Sometimes the criminal suspect may provide false evidence of the crime, or the eyewitness may provide the false

1 Sharan S. Smith, Roger W. Shuy, "Forensic Psycholinguistics: Using Language Analysis for Identifying and Assessing Offenders", FBI Law Enforcement Bulletin April 2002, pp. 15-21. 
testimony. This can be counter-evidenced through the forensic linguistic psychological analysis of the suspect's notes or threatening terms. "Confirmation bias" found by the psychological experiments ${ }^{18}$ confirmed that people have a tendency to distort eyewitness testimony. Therefore, under what circumstances that "seeing is believing" needs to be finally confirmed through the forensic linguistic psychological experiments.

Besides, there is also the case analysis method, laboratory method, site investigation, lie detection, speech analysis, electroencephalography (EEG) and galvanic skin analysis that are commonly used in psychology. Applying the psychological methods to the analysis of the behavior in forensic linguistics is helpful to understand and predict the subject's forensic linguistic behavior, and the legal system provides psychology with a real life laboratory and different research perspectives. It can be said that the most appropriate combination of law, linguistics and psychology will greatly promote the disciplinary development of forensic psycholinguistics.

The future of the application of forensic psycholinguistics is very promising. First of all, forensic psycholinguistics is playing an increasingly important role in the law enforcement investigation. Secondly, employing the methods of forensic psycholinguistics to study high-tech crimes such as those of computer is also becoming a focused topic in academic circles and application fields including China. Some criminals with high-tech background use computer technology to try to hack into the computer systems of government, organizations and private companies to steal confidential documents and information. Although the criminals try to cover up their crimes in the process, however, even the form of computer coding can leave linguistic clues. Psychologists who study behavioral science are conducting a more deepening research on computer crime, which is also a research field well worth developing.

${ }^{18}$ Michael W. Eysenck, Mark T. Keane, Cognitive Psychology, trans. by Gao Dingguo, He Lingnan, East China Normal University, Shanghai 2009. 


\section{The rational thinking on the construction for the ssstem of forensic psscholinguistis}

At present, there is no mature theoretical system of forensic psycholinguistics in China or even in the international community. On the basis of the existing researches in the academic field and combing our own understanding, the authors expect to make the following rational thinking for the construction of the system for forensic psycholinguistics.

\subsection{The main research objects, tasks and methods of forensic psscholinguistics}

Whether a discipline is independent or not, and whether it has disciplinary value mainly depends on its main research objects. From the perspective of psychology, the research objects of forensic psycholinguistics should be individual persons, linguistic interactions and linguistic behaviors among people. However, it is not feasible to regard individual persons, linguistic interactions and linguistic behaviors as the research objects of forensic psycholinguistics. In order to reflect the operability of this discipline, it is necessary to highlight the linguistic behaviors and their interactions in legal activities. The authors think that the research objects of forensic psycholinguistics are linguistic behaviors in such legal activities as legislation, judiciary, law enforcement, law abiding and transgression. Such forensic linguistic behaviors are those that can be expressed by verbal and written form, and can come into force in law and produce legal effects.

Its specific tasks should include the researches on the forensic linguistic behavior at both levels of consciousness and unconsciousness. The level of consciousness includes the cognitive processes of the subject's perception, attention, memory, imagination and thinking of legal language in such activities as legislation, judiciary, law enforcement and law abiding as well as legal publicity; in the process of cognition of legal language, the emotional and affective experience, the individual's volition, motivation, need, belief, attitude, ideal and value and other mental activities and their relationship with legal language; the relationship between legal language and individual's ability, disposition and character. 
The forensic linguistic behavior at the level of unconsciousness mainly refers to those which are below the threshold of consciousness and cannot be realized consciously by people. They include intuition, inspiration, fantasy, dream, mistakes in writing, verbal errors, linguistic failure due to mental problems and body language, all of which are produced in the process of employing legal language; the phenomenon of linguistic psychology and neurophysiology in patients with psychosis and neurosis related to forensic behaviors.

The method of forensic psycholinguistics is to employ the empirical research methods of psychology, through investigation, interview, laboratory experiment, brain science research, use statistical and measurement methods for data analysis and processing, and combine with qualitative research methods to provide scientific basis for the study on the phenomenon of legal language.

\section{3.. The disciplinary interprefetition of forensic psscholinguisitis}

After clarifying the research objects of forensic psycholinguistics, we can expound the psychological phenomena of forensic psycholinguistics in the process of legislation, judiciary, law enforcement, legal publicity and the observance of the law. This is because the creation of the law is achieved through the legislative process, while the implementation of the law is reflected through the process of judiciary, law enforcement, legal publicity and the observance of the law. ${ }^{19}$

\subsubsection{The linguistic psschology of legislation}

It consists of the research on the linguistic psychology and behavior of legislators, the study on people's cognitive mental process of perception, memory, understanding and thinking of legislative language as well as individual and group behaviors, the study on individual's internal mental process, emotional and affective experiences and personal psychology in the cognition of legislative language, the study on whether the words, sentences, structure and style used by

${ }^{19} \mathrm{Wu}$ Buyun, An Introduction to Marxist Philosophy of Right, Shaanxi People's Press, Xian 1992. 
legislators in the legislative process accurately express the public's volition, attitude, need and motivation, and whether they will get the right cognition from the public, and the study on the context, the contemporary appeal and social psychological effects of legislative language.

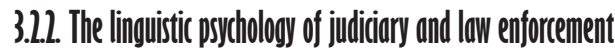

It consists of the study on the psychology and behavior of judicial and law enforcement authorities while using legal language in the process of judiciary and law enforcement, for instance, the forensic linguistic behavior of the courts and procuratorates in handling litigation cases; the linguistic psychology of public security organs in the process of criminal investigation; the psychology of witness testimony; the psychology of defense language; the linguistic psychology in the process of committing a crime; the linguistic psychology of court trial; the linguistic psychology of prisoner reformation; the linguistic psychology of civil mediation the linguistic psychology of civil action, the linguistic psychology of civil trial and the linguistic psychology of civil agency and so on. Besides, according to the different subjects in judicial and law enforcement activities, the linguistic psychology of judiciary and law enforcement also study the linguistic psychology of the criminal defendant, the linguistic psychology of lawyers and judges, the linguistic psychology of the victim, the linguistic psychology of the public prosecutors, the linguistic psychology of policemen, the linguistic psychology of the inquisitors and the forensic linguistic psychology of the investigators and the news media.

\subsection{The linguistic psschology of crime}

It consists of the linguistic psychological activities and its rules of the criminal when an individual commits a crime, for example, the study on the psychological rules of the criminal's pronunciation, intonation, grammar, words and sentences, by means of using cognitive neuroscience instruments to analyze the electrodermal, electroencephalogram, and neurophysiological and psychological activities, the prediction and prevention of criminal psychology through the analysis of criminal linguistic psychology, the study on the psychological features, rules and functions of criminal argot, the study on the relationship between criminal language and 
thinking, emotional and affection, disposition and personality, the study on the context of criminal language, the formation, acquisition and development of criminal language, and the influence of the linguistic activities in family, school and society to criminal psychology.

\subsubsection{The linguisicic psschology of legal publicity and the law abiding}

Legal publicity is the use of language to popularize laws, rules and regulations as well as new laws and regulations enacted by the country, provinces and cities in order to raise people's legal awareness and strengthen lawful behaviors. Researches on criminal psychology have found that many of the alleged perpetrators do not even know it is a crime or are ignorant of the consequences of their actions, among which the imperfection or deficiency of public legal education is one of the important causes of crime. A study by Maxwell Maltz ${ }^{20}$ has shown that a behavior that lasts for 21 days will become a habit, and that if it is carried out for 90 days, it will become a stable and mature habit. Therefore, taking human habits and daily activities as evidence in the court may prove that in some cases, a person or organization acts in accordance with his habits and the rules of his daily activities. The formation of a habit relies on the promotion of language. In China, it still remains a question to be dealt with that whether in family, school or social life, to use appropriate language for legal publicity and help children and teenagers form a habit of abiding the laws. Only by solving the problem of public legal education can we ensure the strict observance of the law by citizens. It is the only way for China to build a law-governed society to master the psychological rules of legal publicity and observing of the law, and to carry out public legal education with appropriate language.

\section{Bibliography}

Bi Xiqian, "Psychological Strategy of Guidance in Criminal Interrogation", Journal of People's Public Security University of China (Social Sciences Edition) 2005, vol. 1, pp. 86-90.

10 Maxwell Maltz, The New Psycho-Cybernetics (Chinese Translation), Qunyan Press, Beijing 2007. 
Eysenck Michael W., Keane Mark T., Cognitive Psychology, trans. by Gao Dingguo, He Lingnin, East China Normal University, Shanghai 2009.

Guo Chengwei, "The Features of the Traditional Legal Languages Embodied in LONG JIN FENG SUI PAN of the Law of Tang Dynasty", The Jurist 2006, vol. 5, pp. 53-58.

Luo Dahua, Judicial Psychology, People's Education Press, Beijing 2005.

Ma Ai, "An Exploration of the Basic Theories in Forensic Psychology", Journal of Gansu Political Science and Law Institute 2010, vol. 4, pp. 51-59.

Maltz Maxwell, The New Psycho-Cybernetics (Chinese Translation), Qunyan Press, Beijing 2007.

Ning Zhiyuan, A Talking about Grammar with Political and Legal Workers, Law Press, Beijing 1982.

Ruan Yuan, Notes on the Thirteen Classics, vol. 4, China Publishing House, Beijing 2009.

Shi Canfang, "A Psychological Analysis of Anomie Phenomena in Advertising Language", Applied Linguistics 1995, vol. 1, pp. 49-51.

Shuy Roger W., Shnukal Anna (eds), Language Use and the Uses of Language, Georgetown University Press, Washington, DC 1996, pp. 222-234.

Smith Sharan S., Shuy Roger W., "Forensic Psycholinguistics: Using Language Analysis for Identifying and Assessing Offenders", FBI Law Enforcement Bulletin April 2002, pp. 15-21.

Song Beiping, Legal Language, China University of Political Science and Law Press, Beijing 2012.

Wu Buyun, An Introduction of Marxist Philosophy of Right, Shaanxi People's Press, Xian 1992.

Xiao Qingping, Yang Xuyin, "A primary Exploration of the Research on Criminal Psycholinguistics", Criminal Research 2001, vol. 5, pp. 31-36.

Xing Wenjun, Research on Inquiring Psychological Language, Police Officer Education Press, Beijing 1997.

Yang Shaogang, "From Forensic Psychology to Forensic Psycholinguistics: A Historical Consideration”, Psychological Research 2011, vol. 4(3), pp. 1-6.

Yang Shaogang, "Zhougong Ji Dan's Thought of Moral Psychology and Its Modern Interpretation", Collected Papers of the Second International Academic Conference on Zhou and Qin Dynasty's Ethical Culture and Modern Moral Values, Shaanxi Normal University Press, Shaanxi 2012.

Zheng Xuan, Notes on Rites of the Zhou, vol. 35, Shanghai Classics Publishing Press, Shanghai 2010. 